\title{
Electronic Musical Instruments: to the Problem of Formation of Performance Mastery
}

\author{
Irina B. Gorbunova
}

\begin{abstract}
The article deals with the formation of the art of performing skills on electronic musical instruments, studied the totality of the educational potential of the modern musical and educational space with the use of electronic musical instruments. The article is devoted to the problems of modern musical performance caused by the development of a number of new artistic trends associated with the evolution of music and its instruments, in which an increasing role today belongs to music computer technologies in the arts - an effective means to improve the quality of teaching musical art at all levels of the educational process, the invention of new musical electronic instruments. The article also deals with the instrumental and technological aspects of music and computer art playback by electronic musical instruments.
\end{abstract}

Keywords-music computer technologies, electronic musical instruments, computer-based music creation, performance art, musical art. s.

\section{INTRODUCTION}

It is known that distrust of the use of computer technology in music was supported by the opinion of almost murderous of its role for the subjective nature of creativity, its spirituality. This view is based on a persistent centuries-old misconception: the technique has never killed creativity, on the contrary, they have developed in close relationship: the whole European musical culture is based on the technique of creating musical instruments. For example, the architecture - acoustics of churches and concert halls - is the technical basis without which vocal and choral music is unthinkable.

For more than 70-year period of time of application of computer technology in musical creativity and musical researches, it has evolved. Initially, computers had relatively small resources-small memory, "slowness" (low speed of information processing). Research at that time followed the path of analysis and creation of musical texts, using a computer studied the "rules" of composition and based on these rules created new compositions. Such "compositions" did not possess (and could not possess) high artistic qualities.

Position fundamentally has changed with the emergence of digital piano. For the first time in decades, pianists gained the opportunity to improve and enrich the methods of learning to play the instrument. With sound quality comparable to acoustic

Irina B. Gorbunova. the Department of Information Technology, Institute of Computer Science and Technological Education of the Herzen State Pedagogical University of Russia and Educational and Methodological Laboratory Music Computer Technologies of the Herzen State Pedagogical University of Russia, St. Petersburg. instruments of the same class, digital instruments had much greater capabilities due to the inclusion of numerous additional devices in their design. Even the simplest digital instruments besides piano sound can imitate harpsichord, organ, string instruments. So, for example, the execution of works or their fragments composers of the 18th -19 th centuries on the "organ or harpsichord", a variety of color effects achieved dynamic and articulation additions, impact directly on the perception of the learner. "The young pianist's auditory experience is enriched by new musical impressions, coloristic effects unusual for the modern musician's hearing. This leads to activation of the associative sphere. In consciousness of the pianist there are new sound standards, means of musical expressiveness. Enriched with musical performances it brings to the area of piano performance, achieving tangible artistic results," writes the musicologist and pianist Victor P. Sradzhev [1, p. 142].

At the same time, attempts were made to control electronic sounds with the help of computer tools, and computer tools and their capabilities were improved.

\section{Music And TeChNOLOgY: Historical CONNECTION}

\section{A. Review Stage}

Developed and technologies for automatic analysis and synthesis of speech, and voice control automation, and the identification of the speaker's voice, and devices for individuals with speech, hearing and vision disorders [2],[3]; analysis and synthesis of living music sounds. However, significant results in these areas could be achieved only with the use of more adequate digital methods of analysis and synthesis of sound (issues of the evolution of music computers (MC) are detailed in the works [4], [5]). In essence, the person "stopped" the sound wave and was able to model its architecture, to look for the deep laws of its structure - to study the architectonics of musical sound [6]-[8]. The main advantage of digital systems for a musician-researcher is the ability to reproduce and easily modify recorded and analyzed "natural" sounds, as well as the ability to create completely new, original sound shapes.

It is known that "synthesized sound" can be a traditional acoustic musical timbre or similar to it, or it can be also absolutely new, not existing earlier, original. The claims that the so-called" synth music " is only within the limits of imitation of traditional musical instruments and musical forms, that synth music is created automatically, mechanically, i.e. without interaction with the musician, are absolutely unreasonable. On the contrary, electronic musical instruments (EMI) expand the palette of the sound of a musical work, and the timbre color of it 
becomes brighter, richer.

At the same time, any, the most perfect musical instrument is a man-made "image", man-made "musical machine" (as Igor Stravinsky writes: "Any musical machine closest to perfection, whether it is a Stradivarius violin or an electronic synthesizer, is useless until it is touched by a person possessing musical skill and imagination" [9, p. 211]), thanks to the interaction with which the sacrament of sound-making takes place, and the musician can Express all the nuances of the sound of a multifaceted timbre space, the emotional "mood" of a person's soul, his feelings, experiences, and the artistic impact of music becomes tangible. The performer tries to convey to the listener the ideas expressed by the composer, and necessarily brings his understanding into the performed work, makes it "alive", complements it, reflecting the modern attitude. In the theory of musical art of the performer's activity is defined as the performance of playback (or interpretation), co-creation, depending on the degree of creative activity of the musician. "A musician-performer in his activity can be even higher than a composer (of course, if his performing experience is higher than that of a composer): he also creates artistic integrity, but not musical, but acoustic. He finds ways to combine or separate sounds, where it is necessary, to "build" the dynamics of development, to emphasize something, to reduce something with the help of volume, high-pitch intonation, timbre, duration, that is, with the help of those means that are not reflected in any or almost no notes" [10, p.28].

Under the "correct" performance of musical works understand the performance, in which method expressions are fully consistent with its content. Josef Hofmann writes that if ten talented performers are given to perform the same play, then each of them will play it "completely differently than the other nine", because each of them seeks to Express in its own way what "he has learned with the mind and heart" [11, pp. 66-67]. The artist-performer must extract from the material designations of music (music notes or other types of music recording) the spiritual essence of the work and pass it to the listeners through the means of a musical instrument, "summon" to the sound life what his musical intellect comprehends. It is thanks to the musical instrument ("the musical machine") that the creative "fusion of composer and performer thought" takes place: "The close connection between music and technology is much more than just an interesting fact. In essence, it is the essence of musical expressiveness" [12, p. 11].

The great musician and teacher Anton Rubinstein in the classroom with his students shouted: "The main thing — that the music sounded as it should, at least even you had to play with your nose!". "Rubinstein did not care about ignis fatuus, - writes Hofmann about the instructions of his teacher - the only correct method. Any method that leads to great artistic results excellent and impressive performance, was acquitted in his eyes" [11, p. 90]. The musician, thus, formulated the basic principles of performing skills, which can be attributed to performing on any musical instrument, including EMI.

\section{The Distinctive FeAtures OF EMI}

Traditional (acoustic) musical instrument is a "collection" of acoustic elements, the mutual relationship between them is established by the structure (construction) of the musical instrument. Acoustic musical instrument is also a complex set of resonators (see details in [13]). The combination of specific masses, the elasticity of individual "parts" of the musical instrument, its geometric shape, the ways of sound production create a unique, inherent in this instrument sound or timbre of the instrument. Over the centuries, new ways of extracting the musical sound and, accordingly, the technology of making new musical instruments, corresponding to the ideas of composers, listening to the sound (music) of the world around them, have been gradually invented. During the 20th century not only a new sound aura was formed, but also in the last decades of the 20th beginning of the 21th century a new area of musical creativity (and education) - music computer technologies (MCT) [14], [15]. With the emergence and development of EMI turned a new page in the history of the development of musical art.

At the heart of any contemporary EMI there is a music computer (or MC) by means of which on one of known technologies [12], [13] the musical sound is synthesized. The EMI controller in such instrument can be made in the form of violin, piano, harp, accordion, etc., can represent any widely known or absolutely new musical instrument; the controller, as such, can be absent at all if there is no need for its use. The main distinctive features of EMI from its predecessors are:

- ability to edit (feedback) the work performed as in the process of its execution and preliminary rehearsals, and when creating new versions of the performing (editions). "Working with electronic editing of versions of performance is a completely new field of activity of the musician-performer of the XXI century. It is based on the specific auditory work of the modern sound engineer pianist, on the stirring up of artistic imagination, imagination, emotional and figurative thinking of the musician in the first place. Electronic edition is an endless variants of the plan. Themselves to "fix" the studio phonogram is interpretations of the work, rather than patching alone random routine mistakes!"[16, p. 11];

- ability to change the configuration of the musical instrument (additional customization options), depending on the specific purpose of the use of such a tool;

- the possibility of creating a sound image of all previous instruments, both individually and the sound of ensembles of instruments and entire symphony orchestras;

- its programmability, i.e. the possibility of creating a preliminary musical material, its recording, preservation and use, if necessary, in the process of subsequent performance;

- through the use of EMI reduces the path to creative comprehension of music. "In an age of unprecedented proliferation of computers, musicians in the days of Gould and, especially, Rakhmaninov, for the first time it is possible to use the edit recording your own games for students to reduce their way to a creative understanding of music. <...> The problem of technique as would be eliminated, removed, or relegated to 
second and third plan" [16, p. 15].

What are the distinctive features of EMI as performing instruments from all previous musical instruments? - In order to answer the question, let us turn to the analysis of the most important aspects of performing skills on the example of piano art. This treatment seems to be justified due to the importance of the piano in the musical culture of the past centuries and the present. EMI, using the key mechanism of sound production, can be considered as a model of development of hammer piano. In recent years, among EMI is one of the most widely used is electronic (digital) piano. The modern electronic piano can be regarded as a tool of the "transition stage" to the development of performing skills on EMI, since the digital piano combines both the properties of its acoustic predecessor and the features of modern EMI.

\section{EMI: THE MAIN BENEFITS}

Despite the relatively short history of EMI functioning, sufficient experience has already been accumulated, and it is possible to identify the following notable features:

- EMI its expressive possibilities are closer to the organ than to the piano;

- EMI combines the many expressive possibilities of organ and orchestra;

- one more function is added for the performer on EMI, namely, the function of the conductor;

- EMI provides additional opportunities for education timbre hearing (orchestral including) for the student;

- EMI creates additional opportunities for a special, deeper immersion in the "artistic content of music", allows a new "read musical text" (Hofmann), to convey the true meaning of the performed musical work [17]-[19];

- there are new, special conditions for the "co-creation" of the composer and performer on EMI;

- thanks to the sequencer built into EMI, perhaps solo artist with orchestra (ensemble) on the keyboard;

- the compactness of this new instrument with a huge variety of musical means of expression allows the use of ensembles EMI;

- thanks to the sequencer, built-in EMI (MC), greatly facilitated the possibility of the development of modern forms of techniques of composition, including the hearing (pointillism, micropolyphony, clusters, polyrhythms, multi-dimensional harmonies, etc.);

- EMI begin to acquire their significant role in the works of contemporary composers, including in the creation of music of academic genres (in the Opera Studio of the St. Petersburg Conservatoire, the premiere of Alexander Chaikovsky's Opera "Three Musketeers", in which two EMI were used as full-fledged elements of the orchestra);

- with the use of EMI in contemporary performing arts, a "new musical aesthetics" (Konstantin Tsaturyan) arises. "The voice of the future" was called EMI composer Rodion Schedrin;

- EMI is one of the most important elements of a computer recording Studio, interacting with its other components, provides an overall artistic result;

- there is a new pedagogy of musical and instrumental performance in connection with the use of EMI in contemporary performing arts;

— EMI and MC become the musician's new instruments;

- with the use of modern models of EMI, the possibility of modeling the patterns of "colored hearing" has appeared»;

- EMI - is a multifunctional tool, it has multi-timbral polyfunctionality;

- thanks to the capabilities of contemporary EMI, the sound space can act as a musical instrument.

Let's consider some of the stated provisions in more detail. The keyboard EMI is closer to the organ than to the piano, and by its expressive possibilities, but EMI 's multithreading is more pronounced than in the organ, thanks to a greater variety of timbres (and greater flexibility in their management) [15], [16]. EMI is of interest as a tool that combines the many expressive possibilities of organ and orchestra. Accordingly, performing practice at EMI involves combining the culture of performance on individual instruments with a creative attitude to timbre, including the problems of its regulation and the creation of new timbres.

\section{Role Of EMI In PERFormer's PERFECTION AND IN EDUCATION OF HEARING}

The process of performing a musical work on EMI creates additional opportunities for the education of timbre hearing, since the approach to the sound of orchestral instruments with the help of contemporary digital technologies is already sufficient to create an adequate general idea of their sound. When performing a piece of music on EMI said earlier about the expressive functions of the piano is projected on the timbre. "Creative approach to work on a digital instrument means a universum well-known during many centuries - first of all, the presence of a creative idea. In the art of piano playing that means an idea of sound imagery: emotionally-semantic, coloristic, temporal, architectonic. First I play as a pianist, and then I work as a studio musician. This gives an extraordinary quality. With each new version of the recorded performance, repetition of the entire piece or its section, and even details is increasingly converging with the higher meaning of musical performance, with its imaginative vision, artistic interpretation" [16, p. 15].

In the performance of music on EMI added another function to the executor, namely, the function of a conductor (for example, the contractor directly at the time of execution of a musical work can realize the adjustment of orchestral balance, adjusting the tempo to make the necessary timbre "retouch", to improve the musical fabric, etc.). Possible new way to "read music" (Hofmann), additional opportunities for special, deeper immersion in the "art musical content" (Tsaturyan) is opened for the performer on EMI, and constant participation in creation of "the whole" gives "deep, steady satisfaction, incomparable feeling of pleasure and confidence in own comprehension of music" [16, p. 15]. 
An extremely important aspect of the performance of a musical work is the process of "co-creation" of the composer and performer. "Without changing any notes, without ignoring any explaning, any remarks of the composer, the performer always has an opportunity in a new way "to read" musical text, to bring the intonation" [10, p. 30]. "Undoubtedly, the composer expressed in his work everything he knew and felt when he wrote it". "Why should we not listen to its specific language?" [11, p. 65]. "Play first exactly what is written; if you have completely paid the credit, and then you still want something to add or change, well, make it" [11, p. 67]. Shchedrin said about the performance of the musical work: "When you create a whole, you do not teach, but participate in the creation of the whole" [20, p. 121]. Glenn Gould exclaims while formulating the main goals of piano mastery: "First of all, I strive to avoid the golden mean immortalized on the plate by many excellent pianists. I think it is very important to emphasize the aspects that cover this work from a completely unusual point of view when recording" [21, p. 25]. According to Hofmann, the performance of a true artist who worked, understood, studied, "felt" the product " should be a free and individual expression, guided only by general laws or rules of aesthetics - otherwise it "will not be artistic and will be deprived of vital force" [11, p. 34].

EMI, being one of the most important elements of a computer recording studio, interacts with its other components, which provide an overall artistic result. It is the editorial version that makes it necessary to interpret the content of the music itself, to find adequate means of its realization. "The possibilities of the digital piano with its sound effects, computer technology of software processing and sound editing lie in a different plane, they are far beyond the "king of instruments" — the acoustic piano. The musical-didactic role of digipiano turns out to be much more important than its concert possibilities" [16, p. 15].

EMI play a significant role in the development of modern artistic and aesthetic performances and musical art in general, are the basis for the formation of new approaches to the interpretation of existing music and the creation of new musical compositions, and they " played a significant role in the development of musical art, serving as the basis for the formation of new classes of phenomena both in the field of its academic direction (electronic, concrete, tape, computer, live electronic music) and mass (rock and pop music)" [22, p. 3]. "The electronic piano is another instrument, it is not like Hammerclavier nor an acoustic piano. And in general, the differences between keyboard synthesizer and piano are much more significant than the differences between piano and organ, or piano and accordion. The digital piano is the piano of the new century. It is rapidly improving. < ... > It is in this area that the music industry is undergoing a historic transition, equal in importance to the change of the harpsichord to the hammer piano in the 19th century. If you look ahead, the sound of the digital piano and the very play on it, in fact, show the beginnings of a new musical aesthetics. The performing "product" itself is interesting and intriguing to the listener, especially our young musicians. It is possible that today the sound of electronic piano in comparison with the usual piano may seem musical exotic. But two hundred and more years ago the harpsichordists also perceived the hammer piano", Tsaturian writes [16, p. 11].

Schedrin was one of the first Russian composers to include the sound of EMI in their musical work. About the creation of music for the play Nina and 12 Months the composer says: "I included in the orchestra instruments balalaika, and to the percussion group I added a lot of Russian instruments: wooden spoons, rattles, cymbal bells Troika (carriage-and-three), etc. an Important role was assigned to the four synthesizers Yamaha-DX7, which were played by two performers, putting the keyboard in front of him" [20, p. 190]. However, for the first time the composer introduced in his work — the ballet "The Hunchbacked Horse" - a synthesizer in the second half of the 50 s of 20 th century. Schedrin calls the sound of EMI "the voice of the future" [23, p. 34].

Mikhail Pletnev on the use of EMI in contemporary performing arts said: "You know that Bach and Beethoven also treated with great interest all the novelties of the development of such a tool as the piano. Bach even participated in the improvement of the piano mechanism. Beethoven wrote a sonata for the emerging Hammerklavier piano immediately after his invention. Even Beethoven's style changed depending on the instrument he played. The fact that the piano can develop further, some new effects will appear in it, new opportunities are very good" [24].

Note that the process of entering any new tool has never been easy. For example, it is known that French educator Voltaire, who recognized only the harpsichord, skeptically nicknamed the piano "pan tool". Music historians, musicians-researchers studying the history of musical instruments, are well aware of the difficulties that were met on the way of "innovations" in this area. It took at least half a century to establish the piano in everyday practice, and even in the 20s of the 19th century, along with the "hammer" piano, his "predecessors"-clavichord and harpsichord - were also widespread. "The problem is as old as the world", Tsaturyan writes. "We have seen that people faced it in the 18th - 19th centuries, when the harpsichord with feathers gradually gave way to a new favorite-the piano with hammers. In fact, these are all different tools. And they sound differently. And they require a different performing approach, a different training. However, perhaps tomorrow the perfect electronic piano will become an everyday phenomenon, as it happened with the acoustic piano and the piano" [16, p. 14].

It should also be noted that in traditional musical culture we are accustomed to understanding a musical instrument as a specific physical object, with which it is possible to create (synthesize) musical sounds of a certain (characteristic) timbre. However, in the field of MCT, in electronic music, the concept of "instrument" defines a wider category of devices: "musical instrument" can be an external sound module with a keyboard, and its rake modification, and the sound module containing hundreds of thousands of "instruments" ("banks" of electronic instrumental sounds). In such a "musical instrument", originally containing tens of thousands of electronic musical 
"instruments", you can download them as many as you like (the choice depends only on the repertoire, the subtlety of the artist's musical perception (as well as the composer, the teacher, the student, the sound engineer, etc.), his needs and artistic and aesthetic taste). It can also be a module with synthesizer and sampler capabilities, and finally, a modern workstation, in fact, MC with a musical keyboard having a DVD-ROM, "equipped" with the necessary software and hardware support.

\section{CONCLUSION}

Thanks to the possibilities of EMI and MC, the sound (acoustic) space itself can be a musical instrument. The timbre side of the sound is known to have spatial characteristics of its reproduction and reflection (see, e.g., [25],[26]) - from the location of sound sources in physical space to the simulation of room acoustics. Hofmann writes: "Your bad mood or a slight indisposition, even insensitive, puritanical harsh or too cold, skeptical audience - all this can be overcome, but the acoustic properties of the hall remaining the same from the beginning of your program to the end, and if they are not your good allies, then turn into an evil demon, mocking all of your efforts to create a noble-sounding picture" [11, p. 53].

Hardware, technical capabilities of modern EMI, presented in the stage musical art, as well as their software support create conditions for the realization of the idea, when the sound space can act as a musical instrument, which the musician has the ability to simulate with the help of his new musical instrument [27],[28]. Edyard Artemyev writes: "For me, the most powerful means of music is space. Early composers did not think about it, they depended on the acoustics of the hall. And it can be built, electronics made it possible. They say that the development of music has reached a deadlock: the scale of sounds is limited by temperament. But the mighty reserve of music-space, the composer can "compose": where, how, where to send the sound, where it will come" [29, p. 59].

Composer and musicologist Valery Beluntsov, answering the question: what EMI is, said: "Any external sound module I want to call the word "instrument", but this is wrong, because it already contains a few dozens of instruments, some instruments can be loaded into it further. What in this case is called "instrument"? This word is called a set of sampled and / or synthesized sounds and parameters for their playback, designed to be controlled via keyboard or MIDI interface. One sound module, external or embedded in the sound card, contains dozens or even hundreds of such sets, and if there is ROM, they can be loaded into it from an external drive. <...> The "tools" that are loaded into memory, can be used as a permanent memory" [30, p. 27]. To control the tone of the sound (its modifications and even its creation) are special frequency filters, which are based on "electronic resonators", raising or lowering the level of different sounds at the request of the musician.

Various aspects of the formation and development of musical instruments reveal the basic laws of the functioning of musical instruments as synthesizers of musical sound in all their diversity from the origins of their formation until the present stage of development of the process.

\section{REFERENCES}

[1] V. P. Sradzhev, "The Use of Digital Piano in the Educational process", Contemporary Musical Education - 2004: Proceedings of the International Research and Practical Conference, ed. Irina B. Gorbunova, pp. 141-142, vol. 2, Saint-Petersburg, 2004.

[2] A. M. Voronov, I. B. Gorbunova, A. Kameris, and L. Yu. Romanenko, "Music computer technologies in the Digital Age School", Proceedings of Irkutsk State Technical University, no. 5(76), pp. 256-261, 2013.

[3] I. B. Gorbunova, L. Yu. Romanenko, and S. V. Chibirev "Modeling of musical creativity process with the use of music computer technologies", Proceedings of Irkutsk State Technical University, no. 4 (75), pp. 16-24, 2013.

[4] I. B. Gorbunova, Music computer: monograph. Saint Petersburg: Publishing house "SMIO Press", 2007. 399 p.

[5] I. B. Gorbunova, Information Technologies in Music, vol. 3: Music computer: course book, Saint Petersburg: Publishing house of the Herzen State Pedagogical University of Russia, 2011, 412 p.

[6] I. B. Gorbunova, Musical sound: monograph, Saint Petersburg: Publishing house "SOYUZ", 2006. 165 p.

[7] I. B. Gorbunova, Information Technologies in Music, vol. 1: Architectonics of musical sound: course book, Saint Petersburg: Publishing house of the Herzen State Pedagogical University of Russia, 2009. $175 \mathrm{p}$.

[8] I. B. Gorbunova, Architectonics of sound: monograph, Saint Petersburg: Publishing house of the Herzen State Pedagogical University of Russia, 2014. $125 \mathrm{p}$.

[9] I. F. Stravinsky, Dialogues, Leningrad: Publishing house "Music", 1971. $414 \mathrm{p}$.

[10] Yu. N. Rags, Levels and content of musicological measurements. Aesthetics: information approach. Moscow: Publishing house Sense, 1997. $224 \mathrm{p}$.

[11] J. Hofmann, Piano game. Answers to questions about piano playing, Moscow: Publishing house Muzgiz, 1961. 215 pp.

[12] D. M. Rabin, The Desktop Musician, Osborne McGraw-Hill, 1995. 272 p.

[13] I. B. Gorbunova, Information Technologies in Music, vol. 2: Music synthesizer: course book, Saint Petersburg: Publishing house of the Herzen State Pedagogical University of Russia, 2010. 205 p.

[14] I. B. Gorbunova, "The Phenomenon of music computer technologies as new creative educational environment", IZVESTIA: Herzen University Journal of Humanities \& Science, no. 4 (9), pp. 123 - 138, 2004.

[15] I. B. Gorbunova, "Music computer technologies in training of the teacher-musician", Music Scholarship / Problemy Muzykal'noj Nauki, no. 3 (16), pp. 5-10, 2014.

[16] K. Tsaturyan, "Contemporary digital piano", Music and Electronics, no. 1 , pp. $13-16,2008$.

[17] I. B. Gorbunova, "New artistic worlds. Interview of Professor of the Herzen State Pedagogical University of Russia I. B. Gorbunova", Music in High School, no. 4, pp. 11-14, 2010.

[18] I. B. Gorbunova, "The Epoch of information technology in the music and creative space", Materials of the 12th St. Petersburg International Conference "Regional Informatics-2010", St. Petersburg, pp. 232 - 233, 2010.

[19] I. B. Gorbunova, M. S. Zalivadny, and I. O. Tovpich "An integrative model for semantic space of music and the prospects of the interaction of musical science and the contemporary musical education", The Scientific Opinion, no. 8, pp. 238-249, 2014

[20] R. K. Schedrin, Autobiographical notes, Moscow: Publishing house News, 2008. 288 p.

[21] G. Gould, No, I'm not an eccentric! Moscow: Publishing house Klassika-XXI, 2003. 124 p.

[22] I. M. Krasilnikov, Musical instruments, Moscow: Publishing house "Art and education", 2007. $98 \mathrm{p}$

[23] R. K. Shchedrin, Monologues over the years, Moscow: Publishing house Composer, 2002. 320 p. [24] M. Pletnev. (18.10.2005, live broadcast). A Night-time Flight. Kultura TV Channel. Available: http:// www.tvkul-tura.ru (accessed on 22.10.2010). 
[24] S. V. Chibirev, I. B. Gorbunova, "Computer modeling of musical creativity process", Proceedings of the Herzen State Pedagogical University of Russia, no. 168, pp. 84-93, 2014.

[25] S. V. Chibirev, I. B. Gorbunova, Music computer technologies: to the problem of modeling the process of musical creativity: monograph, Saint-Petersburg: Publishing house of the Herzen State Pedagogical University of Russia, 2012. 160 p.

[26] I. B. Gorbunova, "Information technologies in music and integrated model of semantic space", St. Petersburg Polytechnic University Journal of Engineering Science and Technology, no. 4 (208), pp. 152 - 161, 2014.

[27] I. B. Gorbunova, "Aesthetics: information approach' by Yu. Rags: relevance and perspectives", Theory and Practice of Social Development, no. 2, pp. 86 - 90, 2015.

[28] E. Artemyev, "Electronics allows you to solve any aesthetic and technical problems", Sound Engineering, no. 2, pp. 56-61, 2001.

[29] V. Beluntsov, Computer for a musician, Saint-Petersburg: Publishing house Peter, 2001. 565 p..

[30] J. U. Duncombe, "Infrared navigation-Part I: An assessment of feasibility," IEEE Trans. Electron Devices, vol. ED-11, pp. 34-39, Jan. 1959

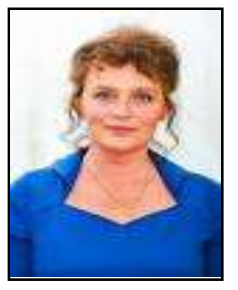

Irina B. Gorbunova was born in Saint Petersburg (Leningrad). DipMus, Special Music Higher School of the St. Petersburg State Conservatory named after N.A. Rimsky-Korsakov; BSc in Computer Science: Information Technology, Computer Science and Multimedia, Leningrad State University, Ussurisk State Pedagogical University; MA in Education, the Herzen State Pedagogical University of Russia; $\mathrm{PhD}$ in Information Technology and Pedagogic Sciences, the Herzen State Pedagogical University of Russia, St. Petersburg, 1989; Doctor degree: Doctor of Pedagogic Sciences and Information Technology, the Herzen State Pedagogical University of Russia, St. Petersburg, 1999. Dr. Gorbunova, Full Professor, PhD in Sc., Doctor of Pedagogic Sciences, Chief Researcher of the Educational and Methodological Laboratory Music Computer Technologies of the Herzen State Pedagogical University of Russia, St. Petersburg.

She was on a number of business trips abroad, among them working trip to the USA (1999); lecturing and giving research and practice seminars in Hungury $(2003,2005,2017)$; business trip to the UK (2016); she was a member of the Jury of national and international competitions of musical creativity, including Bridge of Friendship (Dortmund, Germany, 2011), etc. Work experience; 1990 - 2010 - Associate Professor, Professor of the Department of Information Technology of the Herzen State Pedagogical University of Russia, St. Petersburg; 2010 - present - Full Professor of the Department of Information Technology, Institute of Computer Science and Technological Education of the Herzen State Pedagogical University of Russia, St. Petersburg; 2002 - present - Chief Researcher of the Educational and Methodological Laboratory Music Computer Technologies of the Herzen State Pedagogical University of Russia, St. Petersburg. She has more than 300 scientific publications, among them are monographs Music Computer Technologies: Historical-Theoretical and Practical Aspects, St. Petersburg: Publ. house "SMIO Press" (2007, 560 pp.) and Music Computer Technologies: The Problem of Modeling the Process of Musical Creativity, compiled with participation of S. V. Chibirev, St. Petersburg: Publ. house of the Herzen State Pedagogical University of Russia (2012, 160 pp.); course book Information Technology in Music, vol. 1 - 4: vol. 1, Architectonics of musical sound (2009, 175 pp.), vol. 2, Musical Synthesizers (2010, 205 pp.), vol. 3, Music Computer (2011, 411 pp.), Music, Mathematics and Computer Science, vol. 4, compiled with participation of Mikhail S. Zalivadny (2013, $181 \mathrm{pp}$.), St. Petersburg: Publ. house of the Herzen State Pedagogical University of Russia. Her research activities include such directions as: MCT in professional music education (as a means to expand creative opportunities); MCT in general musical education (as one of the means of education); MCT as a means of rehabilitation of people with disabilities; MCT as the new direction in preparation of specialists of humanitarian and technological profile; MCT in the field of digital arts; MCT in information technology, psychoacoustics and musical acoustics; system of training arrangements and the art of performing skills on electronic musical instruments. Her circle of interests also includes the problems of interrelation of natural and technical sciences and humanities, as well as the possibilities of applying the results of such interrelation for the purposes of music education and upbringing. She also takes part in working out the specialized software for computer music devices and in application of this software in pedagogical processes. Her developments and researches also belong to the field of musical pedagogics and musicology, musical Informatics, computer modeling of processes of musical creativity, timbre programming, art of performing skills and arrangement on electronic musical instruments, creative work in the field of computer music, mathematical methods in musicology.

Prof. Dr. Gorbunova is Chairman of the Organizing Committee of the international research and practice conference Contemporary Music Education, Chairman of the Organizing Committee of the international research and practical conference Music Computer Technologies in the System of Contemporary Education. Dr. Gorbunova is a member of the Jury of national and international competitions of musical creative works, including Electronic Palette (Saint-Petersburg), Music and Electronics (Moscow), Music of the XXI Century (Moscow / Saint-Petersburg), International Festivals and Competitions Musical Electronics and Multimedia (Moscow / Saint-Petersburg), Clarine of the XXI Century (Saint-Petersburg), The World of Art without Borders (Saint-Petersburg, Russia - Szeged, Hungary), Bridge of Friendship (Dortmund, Germany), All-Russian Competition of Electroacoustic Music DEMO (Saint-Petersburg). She is a member of Editorial Boards of International Journals: Music Scholarship / Problemy Muzykal'noj Nauki (SCOPUS), The World of Science, Culture, Education / Mir Nauki, Kul'tury, Obrazovaniya, Electronic international scientific journal of music and sound in electronic mass media, film, Internet, and multimedia MEDIAMUSIC. Prof. Dr. Gorbunova has developed first ever course in Music, called Music Computer Technologies, which has been offered under the Bachelors of Arts and Sciences (BASc), , which in 2004 carried out student recruitment in different regions and educational institutions of Russia and she also leads post-graduate courses "Music Computer Technologies in Education" available under the MA in Music Education, since 2006. Prof. Dr. Gorbunova supervises a number of doctoral and post-doctoral students (more than 30) and lectures on Music Computer Technologies and Information Technology in Music. She supervises research in various directions, among them there are: Theory and history of culture, Music Art, Information system and processes, Theory and methodology of professional education, Mathematical modelling, numerical methods and program systems, Theory and methods of education and upbringing (in Music, Informatics, natural sciences). The research results of Prof. Gorbunova were published in over 300 refereed publications including 48 books and 255 papers in journals and conference proceedings. Awards and honors: 2003 - Gold medal of the all-Russian Exhibition Centre (former VDNKh); 2005 - Silver medal of the all-Russian Exhibition Centre (former VDNKh); 2009 - Gold medal of the all-Russian Exhibition Centre (former VDNKh); 2009 - Diploma of the winner in the nomination «New educational technologies in ICT environment» of the all-Russian creative contest of scientific-technical solutions, educational products and services in the field of Informatization of the innovative-educational complex «Music computer technologies in the system of modern education»; 2010 - Grand Prix of International Congress-exhibition «Global Education - Education Without Borders»; 2010 - Diploma of the 11th all-Russian forum «Educational environment - 2010» for the project «Digital educational resources «Music computer technologies in education» in nomination of «Creative Competition of scientific developments, innovative solutions and programs in the field of higher vocational education» and many others; 2011 - Laureate of the Prize of the Government «For Outstanding Achievements in the Field of Higher and Secondary Professional Education»; 2013 - Honorary Worker of Higher Professional Education of the Russian Federation. 